\title{
Podcasts, Clube de Redação Criativa e Atendimentos Virtuais: novas estratégias para os novos tempos.
}

\author{
Podcasts, Creative Writing Club and Virtual Assistance: new strategies for new times
}

\author{
Priscila Thaiss da Conceição de Medeiros \\ Universidade Federal do Rio de Janeiro - UFRJ - Rio de Janeiro - Brasil
}

\section{Lidiane de Marins Pereira}

Universidade Federal do Rio de Janeiro - UFRJ - Rio de Janeiro - Brasil

\begin{abstract}
Resumo: Este artigo visa a relatar as experiências de ensino de Língua Portuguesa vivenciadas em uma escola municipal da cidade do Rio de Janeiro, durante o período de pandemia causada pelo coronavírus, com alunos de Eja I (anos iniciais) e com alunos dos anos finais do Ensino Fundamental. Com a necessidade de novas ferramentas para nos aproximarmos dos alunos neste período atípico de isolamento social, lançamos mão do uso de podcasts tanto para discutir conteúdos escolares quanto para falar acerca de atualidades e análises de contos. Além disso, criamos o Clube de Redação Criativa na escola e, a partir dele, os atendimentos virtuais aos alunos do Eja I para desenvolvimento da leitura e da compreensão textual. Apresentamos, aqui, quais os objetivos e os procedimentos adotados e quais reflexões foram suscitadas por meio de cada uma dessas experiências.
\end{abstract}

Palavras-chave: Ensino de Português. Leitura e escrita. Eja e Ensino Fundamental II.

Abstract: This article aims to report the Portuguese teaching experience from a public school in Rio de Janeiro, during the corona virus pandemic period, with students from Eja I (beginners) and late-year students from Elementary School. Taking into account the need of new tools to be used in order to get closer to students during such atypical times of social isolation, we started using podcasts both to discuss the syllabus and to talk about current events in addition to analyzing. Furthermore, we created the Creative Writing Club at the school, which resulted in the virtual assistance of Eja I students, aim at the development of reading skills and textual comprehension. We show, here, which objectives and procedures we adopted and which thoughts emerged from each of these experiences.

Keywords: Portuguese teaching. Reading and writing. Youth and Adult Education (EJA) and Elementary school 


\section{Introdução}

O objetivo deste artigo é apresentar as experiências vivenciadas por nós, professoras da Secretaria Municipal de Educação da cidade do Rio de Janeiro, doravante SME, no ensino de Língua Portuguesa durante o período de isolamento social causado pela pandemia da COVID-19. Nossa escola, a Escola Municipal Brigadeiro Eduardo Gomes, atende a alunos dos anos finais do Ensino Fundamental, além de ser a única escola da nossa Coordenadoria Regional de Educação que oferece turmas de Educação de Jovens e Adultos (chamada na rede municipal de Programa de Educação de Jovens e Adultos - Peja) no período diurno. No Peja, atendemos desde alunos na fase de alfabetização até os concluintes do Ensino Fundamental.

Durante o período de isolamento social, sabendo da impossibilidade de atingir a todos os alunos por conta das dificuldades de acesso à internet e a outras ferramentas tecnológicas, e sabendo também da impossibilidade de deixar os alunos que possuem acesso sem algum suporte escolar, fomos orientados pela SME a manter o vínculo com os alunos. A própria SME passou a fornecer apostilas virtuais semanais aos alunos e nós, professores da escola, criamos uma agenda de disciplinas e, a cada dia da semana, uma tarefa era enviada. As tarefas de Língua Portuguesa, por exemplo, eram enviadas às segundas-feiras pelas redes sociais da escola (Facebook e Instagram), grupos de Whatsapp de pais e alunos e pastas de armazenamento em nuvem.

Contudo, percebemos que apenas enviar tarefas não era o suficiente para manter o vínculo com os alunos, visto que ainda havia um abismo entre nós. Além disso, partindo do princípio norteador previsto para a Língua Portuguesa, presente na Base Nacional Comum Curricular, de que:

Ao componente Língua Portuguesa cabe, então, proporcionar aos estudantes experiências que contribuam para a ampliação dos letramentos, de forma a possibilitar a participação significativa e crítica nas diversas práticas sociais permeadas/constituídas pela oralidade, pela escrita e por outras linguagens. (BRASIL, 2017, p. 67 e 68) surgiu a necessidade de novas ferramentas que ampliassem nossa comunicação com os alunos e que nos possibilitasse o trabalho com diversas linguagens, orais e escritas. Assim, os podcasts foram uma solução para que nossas vozes alcançassem os alunos. $\mathrm{Na}$ seção 1, detalharemos como essa ferramenta nos auxiliou, não apenas no trabalho com conteúdos específicos de Língua Portuguesa, mas também com os de outras disciplinas.

Os podcasts foram muito úteis para explicar conteúdos escolares, aprofundar alguma questão trabalhada em exercícios enviados, discutir questões da atualidade e, até mesmo, apresentar a análise de um conto para incentivar a leitura dos estudantes, mas precisávamos continuar a desenvolver as competências linguísticas dos nossos alunos.

Nossa escola valoriza o ensino da leitura, da escrita e das habilidades lógico-matemáticas. Tanto que nosso projeto político pedagógico já há três anos intitula-se "Ler, escrever e calcular, compromisso de todas as áreas", dando ênfase, a cada ano, a um tema. Ano passado o enfoque foi na área de Ciências, por ter sido o Ano Internacional da Tabela Periódica dos Elementos, instituído pela ONU e pela UNESCO, e neste ano o enfoque foi o tema Cidadania. Portanto, nossa equipe, em consonância com as orientações apresentadas pelos Parâmetros Curriculares Nacionais de Língua Portuguesa (BRASIL, 1998, p. 31 e 32 ; p. 41), parte do princípio de que todos os professores são responsáveis pelo desenvolvimento das habilidades linguísticas de leitura e de escrita e pelo desenvolvimento do raciocínio lógico-matemático. Afinal, não é apenas nas aulas de Língua Portuguesa e de Matemática que os alunos precisam ler textos, compreender gráficos, extrair informações de mapas, analisar o discurso de um autor, interpretar uma imagem etc.

Visto a dificuldade que muitos estudantes apresentam em colocar as ideias no papel e desenvolver seu raciocínio por escrito e com a manutenção do período de suspensão das aulas, pensamos em aproveitar a flexibilidade de tempo e a possibilidade do trabalho remoto para desenvolvermos projetos que nem sempre nos eram possíveis na rotina escolar normal. Assim, propusemos à escola a criação 
de um Clube de Redação Criativa, com a inscrição facultativa a todos os alunos, independentemente do ano de escolaridade que estivessem cursando. $\mathrm{Na}$ seção 2, discutiremos o trabalho realizado neste projeto.

Como nossa escola é, majoritariamente, de anos finais do Ensino Fundamental, um grupo se destaca: o Peja I. Esses alunos, apesar de serem os mais velhos em idade, são os mais novos em escolaridade e precisam de uma atenção diferenciada. Como os encontros virtuais do Clube de Redação Criativa estavam funcionando bem, serviram de inspiração para o modelo de atendimento virtual aos alunos do Peja I, quando tarefas que visam a desenvolver a leitura e a compreensão textual passaram a ser executadas e discutidas. Na seção 3, pormenorizaremos essas atividades e 0 funcionamento dos atendimentos.

Finalmente, na seção 4, apresentaremos uma reflexão geral sobre o quanto essas abordagens nos permitiram não apenas manter o vínculo com os alunos, mas principalmente, 0 quanto nos possibilitaram aprimorar as habilidades de leitura e escrita dos nossos estudantes.

\section{Novas ferramentas na escola: o podcast}

Podcast é uma mídia de áudio que lembra muito os programas de rádio. Por meio do podcast, é possível apresentar uma entrevista ou um debate, no caso de mais participantes, ou uma análise individual sobre os mais variados assuntos, como política, esportes, ciências, artes etc. A principal vantagem do podcast é poder ser ouvido a qualquer momento, de acordo com o interesse e a disponibilidade do ouvinte.

A SME já utiliza o podcast há algum tempo, como um dos recursos audiovisuais educativos presentes no portal da MultiRio (http://www.multirio.rj.gov.br/). Contudo, ainda não o havíamos utilizado em nossa escola.

Com o isolamento social e a suspensão das aulas, apenas enviar tarefas, mesmo que de revisão de conteúdo, não garantia que os alunos estivessem entendendo bem a matéria ou o exercício. Nesse momento, em meados de abril, já tínhamos o grupo de pais da escola e as redes sociais, mas ainda não tínhamos todos os grupos de alunos no Whatsapp. Como falar com tantos? Daí, surgiu a ideia do "Brigadeiro Podcast", o podcast da Escola Municipal Brigadeiro Eduardo Gomes.

O primeiro episódio foi ao ar no dia 13 de abril de 2020, como complementação da atividade de sinônimos, destinada aos alunos do 6ํano e do Peja II, blocos 1 e 2. Embora a tarefa fosse especificamente para essas turmas, o podcast era para a escola toda e buscava ampliar os horizontes do exercício, não apenas explicando o que são sinônimos, mas também a sua importância na produção textual.

Daí em diante, passamos a utilizar os podcasts para falar com os alunos. O episódio 2, por exemplo, foi produzido por uma das professoras de Geografia da escola e também regente do Projeto Carioca II, a professora Laurentina Valentim, para tratar sobre como nos tornamos páginas da História, por conta deste momento em que estamos vivendo, e sobre outro acontecimento simultâneo a esse: a alta da maré e o consequente alagamento das ruas da llha do Governador, onde nossa escola está situada e onde a maioria dos nossos alunos reside. A professora aproveitou para explicar a relação das marés com as fases da Lua e, especialmente, com o fenômeno da Superlua.

Foram produzidos podcasts sobre artes, pandemias, meio ambiente, história dos números, questões gramaticais, como encontros consonantais e dígrafos, substantivos e locuções verbais, descrição e vários outros assuntos, inclusive literatura, contando com a participação e colaboração de vários professores da escola e da coordenadora pedagógica, seja enviando sugestões de temas, seja gravando os seus podcasts. Desta forma, os podcasts deixaram de ser apenas uma sugestão nossa, para se tornarem uma ferramenta interdisciplinar, utilizada por toda a escola.

O episódio 1, da série "Vem que eu te conto", foi especial, pois contou com a participação de três professoras, nós, as autoras do artigo, e a professora Laurentina Valentim, apresentando e debatendo o 
conto "Os Esplêndidos Canibais", do livro Contos Peculiares, de Ransom Riggs. Junto com esse episódio, disponibilizamos o livro em formato digital para que os alunos pudessem realizar a sua própria leitura do conto e do resto do livro.

A equipe de Sala de Leitura da escola também aproveitou o uso dos podcasts para apresentar sinopses de livros e sugestões de leitura aos alunos, incentivando-os a ler. Segundo os PCNs, "é necessário que sejam colocados à disposição dos alunos textos dos mais variados gêneros", assim como textos "gravados em áudio e em vídeo, entre outros" (BRASIL, 1998, p.66). Dessa forma, os alunos mantiveram contato com diversos textos através deste material específico.

Finalmente, o material enviado pela escola para participação no Projeto "Tom nas Escolas" foi um podcast realizado a partir do trabalho da professora regente das turmas 171 e 192, ambas do Peja I, em consonância com o Material de Complementação Escolar oferecido pela SME, em que o maestro Tom Jobim estava sendo homenageado pela sua imensa contribuição para a cultura brasileira.

Em uma pesquisa de opinião realizada com os alunos, quase $90 \%$ dos que responderam ao questionário acharam que os podcasts auxiliaram na compreensão das matérias e mais de $85 \%$ acharam os assuntos tratados interessantes. Nessa mesma pesquisa, os alunos sugeriram novos temas, como assuntos relacionados à Ciências e à Matemática e assuntos relacionados às questões emocionais dos alunos durante a pandemia. Houve também sugestão de temas relacionados ao futuro dos alunos, como orientação sobre as diversas profissões.

O isolamento social, portanto, nos permitiu um novo olhar sobre os podcasts. Se antes poderiam ser apenas uma ferramenta a mais para a escola, durante a pandemia se tornaram uma ferramenta essencial para nos dirigirmos a um grande número de alunos, trazendo discussões e apresentando conteúdos que, de outra forma, seria difícil apresentar para tantos alunos a distância.

\section{Clube de Redação Criativa}

O Clube de Redação Criativa foi criado no dia 15 de junho de 2020 e oferecido a todos os alunos da escola que quisessem aproveitar a quarentena para melhorar suas redações. Desta forma, não delimitamos a entrada para o Clube a um ano de escolaridade ou a uma turma em específico. A ideia era contar com a participação do máximo possível de alunos. Alguns se interessaram de pronto e outros entraram com os encontros já iniciados e, até a finalização deste artigo, contávamos com 10 alunos no grupo: 2 do $6^{\circ}$ ano, 3 do $7^{\circ}, 2$ do $8^{\circ}, 1$ do Projeto Carioca II (Projeto de Aceleração da SME) e 2 do Peja I. Desses, 6 alunos estavam conosco desde o início do projeto. Curiosamente, o grupo era majoritariamente feminino, contando com apenas um aluno do sexo masculino, que entrou 2 meses após o início do Clube. Permanecemos anunciando o Clube nas redes sociais da escola e nos grupos de Whatsapp e as inscrições continuaram abertas, durante o período de pandemia e atendimento remoto, a quaisquer alunos que desejassem participar do projeto.

O Clube de Redação Criativa foi criado com o objetivo de proporcionar oportunidades de produção de textos narrativos de gêneros e temas variados para estímulo à escrita, diminuição do medo de escrever, desenvolvimento da criatividade e aprimoramento do texto com relação a questões de estrutura, coesão, coerência, ortografia, pontuação e norma culta. Além disso, objetivamos incentivar a troca de opiniões e experiências entre os alunos e o aumento da autonomia na revisão de seus próprios textos.

Para a prossecução desse objetivo, semanalmente, às segundas, enviávamos um tema pelo grupo de Whatsapp do Clube. O prazo para a devolução das redações findava-se às sextas-feiras de cada semana. No início do projeto, os alunos deveriam enviar apenas a foto com os seus textos, contudo, com o avanço do trabalho, percebemos a falta de releitura por parte dos alunos e a consequente falta de revisão, por isso passamos a solicitar que os alunos também nos enviassem um áudio com a gravação da leitura do seu texto. Durante o áudio, muitos acabavam dizendo: "Peraí que eu errei aqui ", "Deixa eu corrigir algo aqui" ou, ainda, "Ih, errei!", evidenciando questões que os 
alunos não estavam percebendo antes da obrigatoriedade do envio do áudio com a leitura.

Após o recebimento das fotos e áudios, o texto era digitado da forma como estava escrito no papel. As fotos eram enviadas por mensagem privada, evitando, assim, que os outros colegas soubessem de antemão quem foi o escritor de cada texto. Mesmo após a digitação, as redações permaneciam sem identificação. Às segundas, às 14h, nos encontrávamos por meio de videochamada pela plataforma Microsoft Teams, que foi a plataforma disponibilizada pela prefeitura da cidade do Rio de Janeiro para as atividades remotas dos alunos. Durante a videochamada, a tela do computador da professora com a redação era compartilhada com todos.

O procedimento adotado durante os encontros virtuais foi o seguinte: primeiramente, fazíamos uma leitura em voz alta para que todos pudessem conhecer o texto. A seguir, abríamos a discussão para que todos opinassem sobre o texto lido. Esse momento era muito interessante não só pela oportunidade de troca de ideias e incentivo à escrita do colega, mas também porque, muitas vezes, os autores usavam esse momento para dizerem o que acharam que não ficou bom em seus próprios textos. Houve ocasiões em que os alunos, durante os comentários, compararam a escrita do texto recém-lido com outro texto, lido anteriormente no mesmo encontro ou em encontros passados, mostrando que estavam atentos à leitura das redações. Os comentários referiam-se tanto à coerência textual ("Ficou confuso", "Não deu para entender tal parte", por exemplo) quanto a questões ortográficas e gramaticais ("Há algumas palavras erradas”, "Está faltando pontuação aí”, por exemplo).

Um fator que nos causou preocupação nos primeiros encontros foi a possibilidade de haver alguma dificuldade de comunicação entre os alunos pré-adolescentes e os alunos adultos, uma vez que participaram do Clube estudantes cursando desde $06^{\circ}$ ano do Ensino Fundamental regular, com idades entre 11 e 12 anos, até alunos integrantes do Peja, sendo 61 anos a idade da estudante mais idosa. Portanto, um recorte etário amplo. Contudo, essa preocupação passou muito rapidamente, pois os alunos por si só começaram a interagir de forma muito próxima, sem que a diferença de idade interferisse. Algumas vezes, as discussões envolvendo filmes e séries foram tão intensas entre eles que a professora ficou excluída da conversa. Isso só veio a fortalecer o grupo e a contribuir com a aprendizagem de todos.

Após a parte dos comentários, o encontro virtual prosseguia com a releitura do texto, as devidas correções e, se necessário, reescrita. As correções eram, portanto, o momento de intervenção maior por parte da professora. Já a reescrita contava com a colaboração de todos. As partes corrigidas e alteradas em conjunto ficavam destacadas em vermelho, para que os alunos pudessem identificá-las quando recebessem as suas redações corrigidas. Após lermos, comentarmos e corrigirmos todas as redações, cada aluno recebia seu texto corrigido por mensagem privada e novo tema era enviado ao grupo para que pudéssemos dar início à nova semana.

Essa era a rotina do Clube de Redação Criativa, mas é claro que, com o desenvolvimento do projeto e a maior integração do grupo, o processo foi evoluindo e se aprimorando. Inicialmente, por exemplo, os alunos seguiam a orientação de não se identificarem, mesmo que às vezes uns risinhos acabassem dando pistas de quem era o autor. Contudo, já na terceira semana de encontros, alguns alunos resolveram se identificar, alegando não verem motivo para não o fazer. Assim, mantínhamos as redações sem identificação e não anunciávamos o autor caso ele não assumisse a autoria. Se o fizesse, aí sim seguíamos falando mais diretamente com ele, embora todas as explicações fossem para o grupo.

Outra situação que se alterou foi a obrigatoriedade da postagem das redações por mensagem privada para a professora. Com a dificuldade apresentada por alguns alunos em compreender um dos temas, que exigia um texto em $1^{\text {a }}$ pessoa, solicitamos a um integrante permissão para usar seu texto como exemplo para os outros entenderem melhor o que era esperado deles. A partir dessa publicação no grupo e da fala de que outros poderiam ajudar os colegas que estavam com dúvidas, 
os outros alunos começaram a enviar áudios de orientação e enviaram os seus textos, solicitando que os colegas os avaliassem e Ihes avisassem caso as redações não estivessem de acordo com o exigido pelo tema ou caso houvesse erros de escrita. Quando erros eram detectados, o aluno autor dizia que tentaria fazer melhor no próximo e era incentivado pelos colegas não apenas a melhorar, mas também a entender o erro como parte do processo. Esse momento foi bem especial no grupo, pois demonstrou amadurecimento por parte dos integrantes, principalmente daqueles que participavam desde o início do Clube.

Como destacado por Ferrarezi Jr. e Carvalho (2015), um dos problemas das redações escolares é o fato de serem destituídas de seu valor comunicativo, passando a serem vistas apenas como uma tarefa escolar, realizada para entrega ao professor com o objetivo apenas de receber uma nota que permita ao aluno ser aprovado. Como no caso do Clube de Redação não houve atribuição de nota e a participação no Clube era facultativa, minimizou-se a concepção de mera tarefa escolar. Além disso, havia interlocutores dando feedback instantâneo à leitura das redações durante as videochamadas: os colegas do grupo e a professora. Não havia dúvidas, portanto, de que o texto seria lido, pois a leitura ocorria na presença, mesmo que virtual, do autor. Ademais, partiu dos alunos a sugestão de compilar os textos e transformá-los em um livro no final do ano letivo, possibilitando a existência de outros interlocutores: os nossos futuros leitores. A cada produção, lembrávamos aos alunos que deveriam estar atentos aos seus leitores, criando textos claros e interessantes, que prendessem a atenção de quem os fosse ler. Desta forma, houve, durante todo o processo, a preocupação em realmente escrever um texto para comunicar algo a alguém, não para apenas cumprir uma tarefa exigida pela professora. Buscamos, assim, resgatar as funções comunicativas por vezes perdidas nos textos produzidos por alunos na escola.

Outra questão levantada pelos autores Ferrarezi Jr. e Carvalho é que

"É comum que os professores não argumentem com seus alunos sobre as ideias contidas nas redações, não cobrem a responsabilidade dos alunos pelo que escreveram, não façam observações pessoais que conduziriam os alunos a um crescimento intelectual decisivo no exercício de suas vidas nesse mercado de trocas que é a sociedade. Aliás, nesse sentido, a correção da redação se caracteriza como um ato impessoal, que poderia ser levado a efeito por algum bom programa digital de correção ortográfica e gramatical." (FERRAREZI JR. \& CARVALHO, 2015, p. 33)

Embora buscássemos maior apropriação das regras do código escrito, enfocamos a criatividade e a desenvoltura dos textos no Clube de Redação. Por isso, incentivamos os alunos a escreverem, mesmo que essa escrita apresentasse problemas. $\mathrm{E}$ apresentou vários! Mas enfatizamos que o importante era que eles produzissem textos coerentes, claros, interessantes e criativos. Durante a discussão dos textos, chamávamos a atenção para os aspectos do conteúdo, seja o que havia ficado muito bom ou o que precisava de mais atenção. O objetivo primário era esse. Somente depois, mostrávamos os problemas ortográficos e gramaticais, sempre lembrando que a língua escrita é diferente da falada e que, por isso mesmo, possui características próprias que eles, aos poucos, iriam adquirindo. Alguns pediam desculpas pelo "erro" cometido e tentamos deixar claro que "só erra quem tenta" e que eles eram merecedores de congratulações por estarem tentando. Essa postura surtiu efeito com relação à diminuição do medo de escrever, visto que alguns alunos relataram que tinham muito medo e vergonha de escrever por acreditarem que não o sabiam fazer ou por preocupação excessiva com os erros. Com o prosseguimento do projeto, esses mesmos alunos passaram a escrever com mais desenvoltura por terem abandonado esse receio e descobrimos que alguns desses alunos, na verdade, escreviam muito bem. No caso das alunas do Peja I, isso ficou muito claro: elas escreviam bem e passaram a escrever textos cada vez mais encorpados; no início, porém, tinham pavor de escrever e seus textos refletiam esse medo.

As discussões sobre o conteúdo dos textos, em detrimento dos aspectos gramaticais, também 
favoreceram a participação de todos. Afinal, há certo receio, por parte dos alunos em geral, em comentar aspectos gramaticais que "só a professora" sabe corrigir. Contudo, sobre o conteúdo, todos do Clube souberam, puderam e opinaram, o que enriqueceu muito a versão final dos textos. Da mesma forma, nos casos em que houve necessidade de reescrita, os alunos discutiram e colaboraram com o processo, dando sugestões, comparando com outras experiências prévias de livros, filmes e séries. Ao mesmo tempo, se preocuparam se o autor do texto concordava com as sugestões, demonstrando respeito pela produção do colega.

E o mais interessante foi que algumas dessas interações simplesmente aconteceram. Como dito anteriormente, havia a preocupação de nossa parte sobre se haveria algum desentendimento entre os alunos devido às diferentes faixas etárias e experiências de vida. $O$ fato de os alunos estarem atrás de suas câmeras também poderia suscitar esses desentendimentos, como vemos em tantas agressões que ocorrem pela internet. Contudo, passados os primeiros encontros, em que ninguém falava muito, o grupo começou a se integrar de forma muito instigante. No tema 9 - conto de terror, por exemplo, uma aluna teve quatro ideias de enredo para a sua história. Não conseguindo resolver sozinha qual ideia utilizar, ela decidiu, por conta própria, abrir uma votação às cegas no grupo, de modo a ajudá-la a decidir sem acabar com a surpresa do texto. Ela deu um número para cada possível enredo, explicou-nos para que precisava que votássemos e pediu que disséssemos um número de 1 a 4. Conforme escolhíamos um número, ela mandava uma mensagem no privado dizendo qual era o tema no qual havíamos votado. Assim, só quem votou no tema vencedor soube, previamente, sobre qual enredo seria o texto dela. Os outros só souberam durante a videochamada de discussão das redações referentes ao tema 9 . A ideia da aluna ajudou a movimentar bastante o Clube em um dia em que, normalmente, não havia agitação, mais comum às segundas e às sextas.

Talvez, o fato de os alunos terem interagindo bem e com grande respeito entre si se tenha dado exatamente pela interação de alunos de idades tão diferentes, impondo limites aos pré-adolescentes e adolescentes e trazendo, ao mesmo tempo, efervescência aos adultos e idosos.

A quantidade de alunos também foi um diferencial. Gostaríamos de ter contado com um grupo maior de alunos, mas contamos apenas com os que se dispuseram a participar. A dinâmica de uma turma com 10 alunos que desejam fazer parte do grupo funciona de forma completamente diferente da dinâmica de uma turma de 45 alunos cuja maioria não quer fazer parte das atividades.

Com relação aos resultados dessa experiência, pedimos aos alunos que respondessem uma breve pesquisa de opinião sobre o Clube. Todos os alunos disseram estar gostando muito de participar, porque seus textos estavam melhorando e porque gostavam de se comunicar com os outros alunos.

Quando perguntados sobre se percebiam diferenças entre as suas primeiras redações e as mais recentes, em relação à data da pesquisa, $90 \%$ responderam que sim. Na verdade, a única resposta negativa foi dada pelo aluno que entrou por último e, de fato, não houve tempo para que ele pudesse perceber essa diferença.

Com relação a quais diferenças perceberam, os alunos responderam terem notado desde diferenças com relação à pontuação, à paragrafação e à ortografia até diferenças quanto à criatividade, ao tamanho do texto e seu desenvolvimento, à organização da história e à leitura. Esses resultados mostraram que os alunos haviam percebido a mesma evolução nos textos que as professoras.

Os alunos demonstraram estar mais atentos aos detalhes estruturais dos textos, como a paragrafação. No início, alguns alunos não apresentavam paragrafação alguma, outros criavam parágrafos aleatoriamente e outros, ainda, apresentavam um texto centralizado, ou seja, sem respeito às margens iniciais e finais da folha de papel. Com a evolução das produções, os alunos passaram a realizar a paragrafação mais de acordo com o esperado, tanto com relação à disposição do texto na folha de papel, quanto com relação à disposição e 
organização das informações do texto em seus devidos parágrafos. A paragrafação nos casos de discurso direto também apresentou melhora.

Ademais, os alunos passaram a estar mais atentos aos detalhes do desenvolvimento do enredo, preocupando-se em descrever mais os personagens e cenários, em delinear a situação inicial, em criar uma complicação bem elaborada que levasse a um clímax instigante e em apresentar um desfecho coerente. Os alunos evoluíram, ainda, com relação à amarração da história contada, ou seja, passaram a se preocupar em não deixar "pontas soltas" no texto. Nas primeiras redações, acontecia de aparecerem personagens, eventos e objetos que não eram justificáveis na história, pois apareciam e simplesmente não eram retomados. Com o avanço dos temas e encontros virtuais, os alunos passaram a atentar mais a essa questão e, quando porventura alguma informação ficava solta, algum colega logo chamava a atenção para o fato, permitindo que decidíssemos juntos o que fazer: reescrever, amarrando melhor o que havia ficado solto, ou abrir mão da informação não retomada posteriormente no texto. Portanto, o olhar com relação às informações do texto e à sua importância para a história mudou.

Os resultados positivos observados indicaram que o Clube de Redação Criativa conseguiu atingir o seu objetivo de proporcionar melhoria na escrita dos alunos.

\section{Atendimento aos alunos do Peja I}

Como dito anteriormente, a Escola Municipal Brigadeiro Eduardo Gomes atende, além de alunos do Ensino Fundamental regular, os alunos jovens e adultos em sua fase inicial de alfabetização. A escola tem duas turmas de Peja, séries iniciais, com alunos na faixa etária entre 16 e 61 anos, em sua maioria feminina. A turma de Peja I é formada por 11 alunos na turma do bloco 1 e 19 alunos na turma do bloco 2. Desse quantitativo, tínhamos, antes do recesso escolar de meio de ano, a participação de dois alunos do bloco 1 e oito alunos do bloco 2 nas atividades remotas. A pouca adesão ao atendimento virtual se deu pelas dificuldades ao acesso de tecnologias. Os motivos variaram desde a dificuldade de recepção ao sinal de internet, perpassando a falta de aparelhos tecnológicos, como celular ou computador, finalizando com o caso dos que possuíam os aparelhos, porém não se adaptaram a usá-los devido ao tamanho da tela e à baixa visão. Diante desse cenário, a professora regente estabeleceu uma prática pedagógica virtual que atendesse ao grupo de forma satisfatória. Vale ressaltar que, por se tratar de jovens e adultos, as tarefas do cotidiano possivelmente foram triplicadas durante a quarentena, visto que a maioria possui obrigações com cuidados com os familiares, com a casa e compromissos de trabalho mesmo durante o isolamento social.

O grupo de Peja, como qualquer outro, apresenta alguns desafios para a implementação de projetos pedagógicos tanto presencialmente quanto virtualmente. A diversidade na faixa etária se torna uma forte característica da turma. Dessa forma, a seleção de temas, conteúdos e abordagens precisa ser cuidadosa para atender a diversidade do grupo. Para isso, é mantida uma "ação dialógica" (BRANDÃO, 1981) constante para garantir a contextualização e a significação das tarefas propostas.

A escola definiu, em reunião pedagógica, uma abordagem temática interdisciplinar como base para as produções de atividades remotas. Os educadores da unidade produziram atividades relacionadas ao mesmo tema no mês de maio como, por exemplo, o Descarte do Lixo para discutir a ação humana no Meio Ambiente. A escola tem seguido esse mesmo parâmetro até a finalização deste artigo. Sendo assim, como associar os temas definidos pela equipe pedagógica aos interesses e aos conteúdos do Peja? Para isso, a necessidade da contextualização do trabalho tornou-se parte do método pedagógico.

Desde o início do isolamento social em março de 2020, as práticas pedagógicas com o Peja sofreram adaptações. Inicialmente, os alunos receberam a apostila, citada anteriormente, preparada pela SME e disponibilizada na internet. Na fase inicial do trabalho remoto, houve uma adaptação do material da SME de acordo com as necessidades da turma. O retorno dos 
alunos quanto às atividades ocorria via mensagem de Whatsapp através de fotos e áudios, porém a abordagem necessitou de mudanças. Mesmo com a adaptação, os alunos sentiram dificuldades na execução das tarefas. Ao perceber essa necessidade, a professora viu-se obrigada a repensar a prática pedagógica.

Como mencionado antes, o grupo em questão cursa a alfabetização inicial. Portanto, estão em processo de aquisição da leitura alfabética convencional para desenvolvimento de habilidades que permitam o entendimento de determinados comandos e materiais. Daí a dificuldade encontrada pelos alunos em realizar as tarefas da apostila enviada pela SME, mesmo com as adaptações. Por isso, a professora passou a produzir um material específico, pensando nas necessidades do grupo em questão. Esse material foi complementado com o uso da ferramenta apresentada na seção 1 deste artigo: o podcast.

Os podcasts, aliados ao material produzido pela professora, mostraram-se eficazes na complementação das atividades. Além dos novos materiais e dos podcasts, a experiência de sucesso do Clube de Redação Criativa - citado na seção 2 deste artigo - incentivou uma adaptação na forma de atendimento aos alunos: videochamadas semanais para tirar dúvidas sobre os exercícios.

O encontro era mediado da seguinte maneira: o assunto estabelecido para a semana era enviado nos dias combinados e, às quintas-feiras, debatíamos de acordo com as dúvidas que surgiam. Cabe exemplificar a dinâmica dos encontros: os alunos produziam textos narrativos, a partir do tema sugerido, e a correção era realizada durante a chamada de vídeo. A resposta dos alunos a esses encontros foi positiva e funcionou bem até o início do recesso escolar.

Durante o mês de julho, tivemos duas semanas de recesso. Após esse período de pausa nas atividades e com a continuação da suspensão das aulas, houve uma queda no engajamento dos alunos na atividade remota. Os estudantes ficaram desmotivados. Logo, manter o interesse e a dedicação deles às tarefas propostas tornou-se um desafio.

Por meio de ligações telefônicas e mensagens no privado para entender os motivos da dispersão dos alunos, a professora conseguiu manter a participação de cinco dos dez alunos que participavam inicialmente da realização das atividades enviadas e das videochamadas.

Embora esse não seja o número ideal, os alunos que se mantiveram ativos demonstraram bastante interesse e comprometimento com as tarefas. Assim, progrediram no desenvolvimento de suas competências linguísticas.

O grupo de alfabetização inicial possui um aluno com necessidades especiais que não conseguia organizar seu material de estudo no início das atividades a distância e, com o desenvolvimento do atendimento à sua turma, conseguiu se organizar com autonomia, mesmo com apoio da professora. Além disso, algumas habilidades que já haviam sido conquistadas, como a escrita do nome próprio, e que estavam se perdendo, foram resgatadas com 0 atendimento pelas videochamadas. Desta forma, o atendimento virtual a esse aluno segue em conformidade ao regulamentado pelo Decreto $\mathrm{n}^{\circ}$ 7.611, que dispõe que o atendimento educacional especializado deve ser fomentado pelo "desenvolvimento de recursos didáticos e pedagógicos que eliminem as barreiras no processo de ensino e aprendizagem." (BRASIL, 2011, artigo III, inciso III).

Já os alunos do bloco 2, que estão em nível avançado de alfabetização, tiveram o atendimento focado no desenvolvimento das habilidades de leitura e escrita, com a valorização de suas experiências prévias e com a contextualização do conhecimento por campos de atuação, especialmente o campo da vida cotidiana, como preconizado pela BNCC (BRASIL, 2018, p. 84). Além dos avanços relacionados ao uso das tecnologias, destacou-se a melhora na fluidez da leitura em voz alta, no entendimento de textos variados e na produção escrita. A partir disso, os alunos se sentiram mais confiantes a ponto de aceitarem participar do II Sarau Virtual de Poesia, organizado pela Sala de Leitura da escola, que exigiu não só a 
leitura de um poema, mas sua leitura em voz alta para pessoas com as quais os alunos não tinham contato próximo, como as professoras da Sala de Leitura e a coordenadora pedagógica.

Dentre os alunos do bloco 2, percebeu-se que as duas alunas que participavam do Clube de Redação Criativa, além dos encontros com sua turma do Peja, passaram a se sentir desafiadas a escreverem melhor, provavelmente pelo contato com as produções dos outros alunos, o que só veio a ratificar o quanto a troca de experiências entre os alunos de idades, anos de escolaridade e vivências diferentes foi frutífera para os integrantes do Clube.

Em suma, os atendimentos virtuais foram um desafio devido a questões socioculturais e a limitações de uso de tecnologias da informação e comunicação. Ainda assim, os resultados obtidos neste período de distanciamento se mostraram positivos, mesmo com toda a excepcionalidade vivenciada durante a pandemia.

\section{Reflexões finais}

Consideramos as metodologias e as experiências do atendimento remoto executadas durante o período de isolamento social causado pela pandemia da Covid-19 uma prática consonante com as práticas descritas na BNCC (BRASIL, 2017), ou seja, de acordo com o documento proposto para nortear o desenvolvimento das habilidades no Ensino Fundamental. Consideramos satisfatório o retorno dos educandos quanto aos materiais produzidos e quanto aos atendimentos por videochamada. Contudo, o quantitativo de estudantes participantes foi menor do que o desejado.

Os diálogos entre os educandos e as professoras foram imprescindíveis para o resultado dessas experiências. A equipe diretiva, as educadoras responsáveis pela Sala de Leitura, assim como os demais professores, apoiaram o projeto dos podcasts, contribuindo para a produção de conteúdos variados. O suporte oferecido pela equipe pedagógica permitiu uma experiência múltipla e significativa para o corpo discente.
Em síntese, acreditamos que o trabalho desenvolvido superou as expectativas quanto à efetiva implantação, mesmo com um grupo reduzido de alunos. O contato mais estreito com os alunos foi de extrema importância aos que procuraram auxílio e aos que se envolveram nas atividades e projetos propostos. O cenário imposto pela crise mundial de saúde afetou as nossas metodologias usuais de sala de aula. Porém, nos proporcionou a possibilidade de explorar novos caminhos para atingir os alunos.

\section{REFERÊNCIAS}

BRANDÃO, C.R. O que é método Paulo Freire. São Paulo. ed. Brasiliense, 1981.

BRASIL. Base Nacional Comum Curricular (BNCC). Educação é a Base. Brasília, MEC/CONSED/UNDIME, 2017. Disponível em: < 568 http://basenacionalcomum.mec.gov.br/images/BNCC_ publicacao.pdf>. Acesso em: 30 de julho de 2020.

BRASIL. Decreto no 7,611, de 17 de novembro de 2011. Dispõe sobre a educação especial, o atendimento educacional especializado e dá outras providências. Diário Oficial da República Federativa do Brasil, Brasília, n.221, p. 12, col. 1, 18 de nov. de 2011. BRASIL. Secretaria de Educação Fundamental. Parâmetros curriculares nacionais: terceiro e quarto ciclos do ensino fundamental: língua portuguesa. Brasília: MEC/SEF, 1998.

FERRAREZI JR., Celso; CARVALHO, Roberto Santos de. Produzir textos na educação básica: o que saber, como fazer. 1. ed. São Paulo: Parábola Editorial, 2015.

DE MEDEIROS, Priscila Thaiss da Conceição; PEREIRA, Lidiane de Marins. Podcasts, Clube de Redação Criativa e Atendimentos Virtuais: novas estratégias para novos tempos. Signo, Santa Cruz do Sul, v. 46, n. 85, p. 48-57, jan. 2021. ISSN 1982-2014. Disponível em: $<$ https://online.unisc.br/seer/index.php/signo/article/view/1570 6>. doi:https://doi.org/10.17058/signo.v46i85.15706. 